\title{
Effect of regulatory warnings on antipsychotic prescription rates among elderly patients with dementia: a population-based time-series analysis
}

\author{
Elmira Valiyeva PhD, Nathan Herrmann MD, Paula A. Rochon MD MPH, Sudeep S. Gill MD MSc, \\ Geoffrey M. Anderson MD PhD
}

$\infty$ See related commentary by Katz, page 405

\section{ABSTRACT}

Background: Three warnings of serious adverse events associated with the use of atypical antipsychotic drugs among elderly patients with dementia were sent to health care professionals in Canada. We assessed the impact of these warnings on prescription rates of antipsychotic drugs in this patient population.

Methods: We used prescription drug claims data from Ontario to calculate prescription rates of atypical and conventional antipsychotic drugs among elderly patients with dementia from May 1, 2000, to Feb. 28, 2007. We performed a time-series analysis to estimate the effect of each warning on rates of antipsychotic drug use.

Results: Before the first warning, growth in the use of atypical antipsychotics was responsible for an increasing rate of overall antipsychotic use. Each warning was associated with a small relative decrease in the predicted growth in the use of atypical antipsychotic drugs: a 5.0\% decrease after the first warning, $4.9 \%$ after the second and $3.2 \%$ after the third (each $p<0.05$ ). The overall prescription rate of antipsychotic drugs among patients with dementia increased by $20 \%$, from 1512 per 100000 elderly patients in September 2002, the month before the first warning, to 1813 per 100000 in February 2007, 20 months after the last warning.

Interpretation: Although the warnings slowed the growth in the use of atypical antipsychotic drugs among patients with dementia, they did not reduce the overall prescription rate of these potentially dangerous drugs. More effective interventions are necessary to improve postmarket drug safety in vulnerable populations.

Une version française de ce résumé est disponible à l'adresse www.cmaj.ca/cgi/content/full/179/5/438/DC1

CMAJ 2008;179(5):438-46

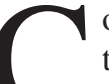
oncern is growing over the effectiveness of actions taken by drug regulatory agencies on safety information that becomes available to them after a drug has been licensed and marketed. ${ }^{1-3}$ Drug regulators such as
Health Canada hope that disseminating information on new safety concerns through "Dear Healthcare Professional" letters will shift how the stakeholders involved in drug utilization - manufacturers, public and private insurers, pharmacists, physicians and the public — think about the trade-off between risks and benefits. Ultimately, this should lead to safer prescribing decisions.

The introduction of newer, atypical antipsychotic drugs risperidone, olanzapine and quetiapine — in the 1990s was heralded as a breakthrough in the treatment of schizophrenia and other psychiatric conditions. All 3 of these drugs were approved by Health Canada for the treatment of schizophrenia, but only risperidone was approved for short-term symptomatic management of inappropriate behaviour due to aggression or psychosis in patients with severe dementia.

On Oct. 11, 2002, Janssen-Ortho, the drug company that markets risperidone in Canada, after discussion with Health Canada, sent a letter to health professionals warning of safety concerns with the use of risperidone in elderly patients with dementia. On Mar. 10, 2004, Eli Lilly, the manufacturer of olanzapine, after discussion with Health Canada, sent a letter to health professionals warning of safety concerns with the use of olanzapine in elderly patients with dementia. On June 22, 2005, Health Canada circulated a letter warning health professionals of safety concerns with the use of risperidone, olanzapine or quetiapine in elderly patients with dementia. The content of the 3 warnings is summarized in Table 1; the full text of the letters is available online from Health Canada. $^{4-6}$

We sought to examine the effects of these warnings on the use of the atypical antipsychotic agents mentioned in the warnings as well as the use of conventional antipsychotic drugs.

From the Department of Health Policy, Management and Evaluation (Valiyeva, Rochon, Anderson), University of Toronto, Toronto, Ont.; the Institute for Clinical Evaluative Sciences (Valiyeva, Rochon, Gill, Anderson), Toronto, Ont.; the Division of Geriatric Psychiatry (Herrmann), Sunnybrook Health Sciences Centre, Toronto, Ont.; the Departments of Psychiatry (Herrmann) and Medicine (Rochon), University of Toronto, Toronto, Ont.; the Kunin-Lunenfeld Applied Research Unit, Baycrest (Rochon), Toronto, Ont.; and Providence Healthcare, Queen's University (Gill), Kingston, Ont. 


\section{Methods}

\section{Study cohort}

We obtained data from the Ontario Drug Benefit database on all prescription drug claims submitted from May 1, 2000, to Feb. 28, 2007, for the 3 newer, atypical antipsychotic drugs (risperidone, olanzapine and quetiapine) and a list of older conventional antipsychotic drugs (a complete list of these drugs is available in Appendix 1, at www.cmaj.ca/cgi/content /full/179/5/438/DC2). The Ontario Drug Benefit program covered without restriction the use of the 3 atypical antipsychotic drugs and all of these conventional agents for patients 65 years of age and older for the entire study period.

We included conventional antipsychotic agents in light of the results of observational studies suggesting that the risk of death associated with these drugs is greater than the risk asso-

Table 1: Characteristics of 3 warnings of serious adverse events associated with the use of atypical antipsychotic drugs in elderly patients with dementia

\begin{tabular}{|c|c|c|c|}
\hline Characteristic & $\begin{array}{c}\text { First warning } \\
\text { (issued Oct. 11, 2002) }\end{array}$ & $\begin{array}{c}\text { Second warning } \\
\text { (issued Mar. 10, 2004) }\end{array}$ & $\begin{array}{l}\text { Third warning } \\
\text { (issued June 22, 2005) }\end{array}$ \\
\hline Source & $\begin{array}{l}\text { - Letter to health care } \\
\text { professionals sent by Janssen- } \\
\text { Ortho following discussion with } \\
\text { Health Canada }\end{array}$ & $\begin{array}{l}\text { Letter to health care } \\
\text { professionals sent by Eli Lilly } \\
\text { following discussion with Health } \\
\text { Canada }\end{array}$ & $\begin{array}{l}\text { - Letter to health care professionals } \\
\text { sent by Health Canada }\end{array}$ \\
\hline Subject & $\begin{array}{l}\text { Risperdal (risperidone) and } \\
\text { cerebrovascular adverse events } \\
\text { in placebo-controlled trials } \\
\text { involving patients with dementia }\end{array}$ & $\begin{array}{l}\text { Zyprexa (olanzapine) and } \\
\text { cerebrovascular adverse events } \\
\text { in placebo-controlled trials } \\
\text { involving elderly patients with } \\
\text { dementia }\end{array}$ & $\begin{array}{l}\text { - Increased mortality associated with } \\
\text { use of atypical antipsychotic drugs } \\
\text { among elderly patients with } \\
\text { dementia }\end{array}$ \\
\hline $\begin{array}{l}\text { Advice } \\
\text { provided }\end{array}$ & $\begin{array}{l}\text { - Physicians advised to reassess risk } \\
\text { and benefits of use of Risperdal } \\
\text { in elderly patients with } \\
\text { dementia } \\
\text { - Physicians advised to counsel } \\
\text { patients and caregivers to report } \\
\text { signs and symptoms of potential } \\
\text { cerebrovascular adverse events } \\
\text { immediately so that diagnosis } \\
\text { and management decisions, } \\
\text { including treatment } \\
\text { discontinuation, can be made } \\
\text { without delay }\end{array}$ & $\begin{array}{l}\text { - Physicians advised to reassess risk } \\
\text { and benefits of use of Zyprexa in } \\
\text { elderly patients with dementia } \\
\text { - Physicians advised to counsel } \\
\text { patients and caregivers to report } \\
\text { signs and symptoms of potential } \\
\text { cerebrovascular adverse events } \\
\text { immediately so that diagnosis } \\
\text { and management decisions, } \\
\text { including treatment } \\
\text { discontinuation, can be made } \\
\text { without delay }\end{array}$ & $\begin{array}{l}\text { - Canadians advised that treatment } \\
\text { with atypical antipsychotic } \\
\text { medication of behavioural } \\
\text { disorders in elderly patients is } \\
\text { associated with increased risk of } \\
\text { all-cause mortality }\end{array}$ \\
\hline $\begin{array}{l}\text { Evidence } \\
\text { provided }\end{array}$ & $\begin{array}{l}\text { - Summary of results from } 4 \\
\text { placebo-controlled randomized } \\
\text { trials showing } 2 \% \text { absolute risk } \\
\text { of cerebrovascular adverse } \\
\text { events with Risperdal use }\end{array}$ & $\begin{array}{l}\text { - Summary of results from } 5 \\
\text { placebo-controlled randomized } \\
\text { trials showing } 0.9 \% \text { absolute risk } \\
\text { of cerebrovascular adverse } \\
\text { events with Zyprexa use } \\
\text { - The efficacy of Zyprexa in elderly } \\
\text { patients with dementia-related } \\
\text { psychosis has not been } \\
\text { established in clinical trials }\end{array}$ & $\begin{array}{l}\text { - Summary of results from } 13 \\
\text { placebo-controlled randomized } \\
\text { trials of risperidone ( } 6 \text { trials), } \\
\text { quetiapine ( } 2 \text { trials) and } \\
\text { olanzapine ( } 5 \text { trials) showing } \\
\text { increased absolute risk of all-cause } \\
\text { mortality with risperidone }(0.9 \%) \text {, } \\
\text { quetiapine }(2.3 \%) \text { and olanzapine } \\
(2.0 \%) \text { among elderly patients } \\
\text { with dementia }\end{array}$ \\
\hline $\begin{array}{l}\text { Other } \\
\text { information } \\
\text { provided }\end{array}$ & $\begin{array}{l}\text { There is insufficient information } \\
\text { to determine whether the risk of } \\
\text { cerebrovascular adverse events is } \\
\text { associated with Risperdal, all } \\
\text { antipsychotics or any particular } \\
\text { type of dementia } \\
\text { - Current prescribing information } \\
\text { for Risperdal includes warning of } \\
\text { caution about use in patients } \\
\text { with cardiovascular disease }\end{array}$ & $\begin{array}{l}\text { - There is insufficient information } \\
\text { to determine whether the risk of } \\
\text { cerebrovascular adverse events is } \\
\text { associated with Zyprexa or all } \\
\text { antipsychotics } \\
\text { - The risk of cerebrovascular } \\
\text { adverse events may be } \\
\text { associated with vascular or } \\
\text { mixed-type dementia } \\
\text { - Zyprexa approved for the } \\
\text { treatment of schizophrenia but } \\
\text { not for the treatment of } \\
\text { dementia-related psychosis } \\
\text { - Current prescribing information } \\
\text { for Zyprexa includes warning of } \\
\text { caution about use in patients } \\
\text { with cardiovascular disease }\end{array}$ & $\begin{array}{l}\text { - All atypical antipsychotics are } \\
\text { approved for the treatment of } \\
\text { schizophrenia, but only } \\
\text { risperidone is approved for ishort } \\
\text { term symptomatic management of } \\
\text { inappropriate behaviour due to } \\
\text { aggression and/or psychosis in } \\
\text { patients with severe dementia" } \\
\text { - Most of the deaths were due to } \\
\text { heart-related events or infections }\end{array}$ \\
\hline
\end{tabular}


ciated with atypical antipsychotic agents. ${ }^{78}$ In this context, examination of the overall use of antipsychotic drugs, conventional and atypical, should provide a comprehensive measure of the impact of the warnings on patient safety.

The Ontario Drug Benefit database contains claims for prescription drugs submitted by pharmacists for reimbursement. Each claim contains information on the drug, the date on which the drug was dispensed, whether the patient was in a nursing home and a unique claimant identifier. The claims have very low error rates for data on the drugs and dates dispensed..$^{9}$

We sorted the claims by date and by unique claimant identifier. To identify patients with a history of dementia, we linked the unique identifier from the drug claim to hospital discharge abstracts from the Canadian Institute for Health Information and physician claims data from the Ontario Health Insurance Plan in the 5 years before the date of the drug claim to look for a dementia-related diagnosis. We also looked for claims for cholinesterase inhibitors (a class of drugs used only in patients with dementia to treat cognitive decline) submitted to the Ontario Drug Benefit program in the year before the antipsychotic drug claim. We have used this technique to identify patients with dementia in previous research, and the details can be found in a previous publication. ${ }^{10}$

We obtained demographic information (age and sex) by linking the unique identifiers from the drug claims to the Registered Persons Database of the Ontario Health Insurance Plan. The Ontario Drug Benefit Program covers individuals 65 years and older. Therefore, to assess use of drugs to treat dementia in the year before the drug claim, we limited the study population to patients 66 years and older at the time of each prescription.

\section{Prescription rates}

We used unique drug identification numbers (DINs) to assign claims into 6 drug categories: risperidone; olanzapine; quetiapine; atypical antipsychotic agents (risperidone, olanzapine or quetiapine); conventional antipsychotic agents; and all antipsychotic agents. We calculated separate monthly counts for each of these groups.

To calculate the prescription rates, we divided the number of unique individuals per month with a history of dementia who were dispensed at least one prescription for the drug or drugs of interest by the Ontario population aged 65 years and older. The Ontario population was linearly interpolated for each month from annual Statistics Canada population estimates.

\section{Data analysis}

The 3 warnings were well spaced from each other and divided the study period into 4 segments, each with multiple observations: the period before the first warning (from May 2000 to September 2002); the period after the first warning (from October 2002 to February 2004); the period after the second warning (from March 2004 to May 2005); and the period after the third warning (from June 2005 to February 2007).

We used interrupted time-series analysis to estimate the impact of the 3 warnings on prescription rates. We used the multiple observations of monthly prescription rates over the study period to estimate models that had intercept and slope terms for the period before the first warning and intercept and slope terms for each of the 3 warnings. This type of model divides the data into segments that allowed us to estimate the effect of the warnings. ${ }^{11} \mathrm{We}$ measured the effect of each warning by comparing the prescription rate 12 months after the warning, estimated from the full model, with a predicted prescription

Table 2: Characteristics of elderly patients with dementia prescribed antipsychotic drugs from May 2000 to February 2007

\begin{tabular}{|c|c|c|c|c|c|}
\hline \multirow[b]{2}{*}{ Characteristic } & \multicolumn{5}{|c|}{ Period; no. (\%) of patients* } \\
\hline & $\begin{array}{l}\text { First month of } \\
\text { observation period } \\
\text { (May 2000) }\end{array}$ & $\begin{array}{l}\text { Month before } \\
\text { first warning } \\
\text { (September 2002) }\end{array}$ & $\begin{array}{l}\text { Month before } \\
\text { second warning } \\
\text { (February 2004) }\end{array}$ & $\begin{array}{l}\text { Month before } \\
\text { third warning } \\
\text { (May 2005) }\end{array}$ & $\begin{array}{l}\text { Last month of } \\
\text { observation period } \\
\text { (February 2007) }\end{array}$ \\
\hline Total no. of patientst & 16066 & 23056 & 26716 & 29381 & 30029 \\
\hline \multicolumn{6}{|l|}{ Age, yr } \\
\hline Mean (standard deviation) & $81.9(7.4)$ & $82.3(7.4)$ & $82.4(7.3)$ & $82.5(7.6)$ & 82.7 (7.6) \\
\hline Patients $\geq 85 \mathrm{yr}$ & $6228(38.8)$ & $9253(40.1)$ & $10682(40.0)$ & $11856(40.4)$ & 12567 (41.8) \\
\hline Sex, male & $4716(29.4)$ & $6923(30.0)$ & $8141(30.5)$ & $9095(31.0)$ & $9173(30.5)$ \\
\hline Nursing home resident & $11246(70.0)$ & 16125 (69.9) & $18859(70.6)$ & $20566(70.0)$ & $21181 \quad(70.5)$ \\
\hline \multicolumn{6}{|l|}{ Drug prescribed } \\
\hline Risperidone & 7311 (45.5) & 12402 (53.8) & $13203(49.4)$ & 14178 (48.3) & $13757(45.8)$ \\
\hline Olanzapine & 3409 (21.2) & $6060(26.3)$ & 7375 (27.6) & $7253(24.7)$ & $6691(22.3)$ \\
\hline Quetiapine & $381 \quad(2.4)$ & 3101 (13.4) & $5435(20.3)$ & $7559(25.7)$ & 9573 (31.9) \\
\hline $\begin{array}{l}\text { Conventional } \\
\text { antipsychotic }\end{array}$ & $5628(35.0)$ & $2531(11.0)$ & $1932 \quad(7.2)$ & 1669 & 1573 \\
\hline $\begin{array}{l}\text { Rate of use per } 100000 \\
\text { population aged } \geq 65 \mathrm{yr}\end{array}$ & 1102 & 1512 & 1703 & 1831 & 1813 \\
\hline
\end{tabular}

*Unless stated otherwise.

TThis is the number of patients who received any antipsychotic prescription in that month. It is not equal to the sum of the number of patients in each drug category, since a patient may have been counted in more than 1 category. 
rate for which we assumed that the warning had no effect (i.e., the intercept and slope terms for that warning were set to zero). We calculated the absolute effect of each warning as the difference between the estimated and predicted rates 12 months after the warning. We calculated the relative effect of each warning as the absolute difference 12 months after the warning divided by the predicted rate 12 months after the warning.

Time-series analysis requires the definition, testing and interpretation of the model. The details of the analysis, model definition and testing are provided in Appendix 2 (available at www.cmaj.ca/cgi/content/full/179/5/438/DC2).

\section{Ethics review}

The study design was approved by the Ethics Review Board of the Sunnybrook Health Sciences Centre.

\section{Results}

Table 2 contains data on the monthly counts and selected characteristics of elderly people with dementia who received antipsychotic drugs in May 2000 (baseline), in the month before each warning and in February 2007 (the last month of the observation period). In September 2002, the month before the first warning, just over 23000 patients received a prescription for an antipsychotic drug. In February 2007, after the 3 warnings, just over 30000 patients were dispensed an antipsychotic drug. Over this period, the rates of use increased by $20 \%$, from 1512 per 100000 population 65 years and older to 1813 per 100000 .
Over the study period, about $70 \%$ of the individuals receiving antipsychotic drugs lived in nursing homes, and about $40 \%$ were over 85 years of age. The proportions of patients who received risperidone (about 45\%) and olanzapine (about 22\%) were comparable in May 2000 and February 2007. The proportion of patients who received conventional antipsychotic agents decreased, from 35.0\% in May 2000 to $5.2 \%$ in February 2007. The proportion who received quetiapine increased, from $2.4 \%$ in May 2000 to $31.9 \%$ in February 2007.

The segmented regression analyses are presented in Figure 1, Figure 2, Figure 3, Figure 4, Figure 5 and Figure 6. Each figure represents data on one of the drug categories studied. The figures contain data on the observed monthly prescription rates, the prescription rates estimated from the time-series regression model for the entire study period, and the prescription rates predicted from the model for the 12 months after each warning assuming that the warning had no effect. From May 2000 until the first warning in October 2002, the prescription rates of antipsychotic drugs overall and for each of the atypical antipsychotic drugs were increasing, whereas the rates for conventional antipsychotic agents were decreasing.

The absolute and relative effects on the prescription rates 12 months after the warnings are presented in Table 3. The first warning was associated with significant decreases in the predicted growth in the use of risperidone, the drug specifically mentioned in that warning. It was also associated with significant decreases in the predicted growth in olanzapine use and increases in the predicted growth in quetiapine use.

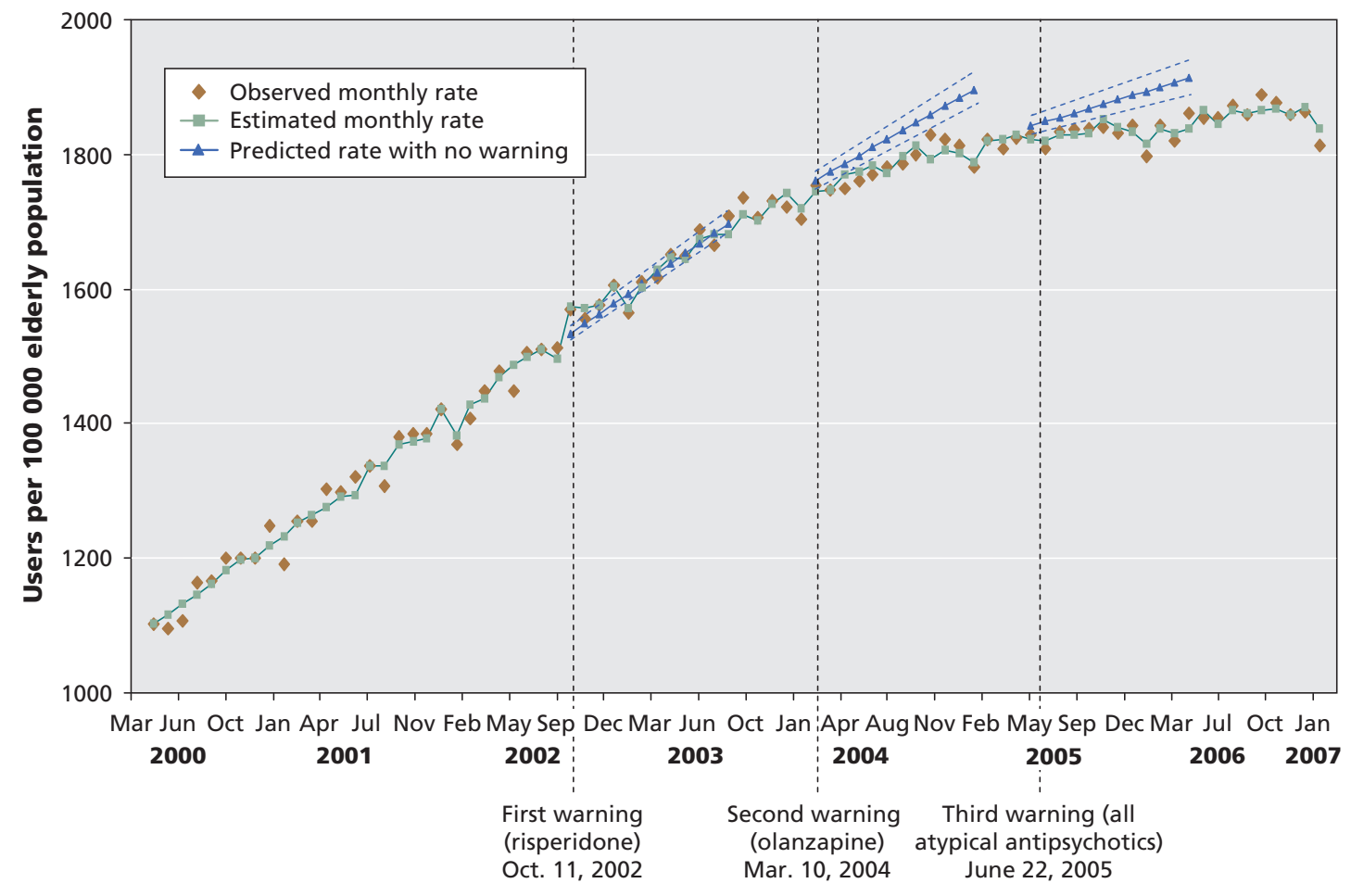

Figure 1: Estimated and predicted use of antipsychotic drugs overall before and after 3 warnings of serious adverse events associated with atypical antipsychotic drugs in elderly patients with dementia. Estimated rates, and predicted rates without warnings, represent estimates from our interrupted time-series analysis. The dashed blue lines represent $95 \%$ confidence intervals around the predicted estimates. 
Overall, there was a decrease in the predicted growth in the use of the 3 atypical agents combined. The first warning was also associated with a slowing in the predicted decline in use of conventional agents.

The second warning named only olanzapine and was associated with significant decreases in the absolute and relative growth in its use (Table 3). It was also associated with a decrease in the predicted growth in the use of atypical agents and of antipsychotic drugs overall.

The third warning, which mentioned all 3 atypical antipsychotic agents, was associated with a relative decrease in the predicted growth in quetiapine use, a relative decrease in the predicted growth in the use of atypical agents, and absolute and relative decreases in the predicted growth in the use of antipsychotic drugs overall (Table 3 ).

\section{Interpretation}

We found that the 3 warnings about serious adverse events associated with use of atypical antipsychotic agents in elderly people with dementia had a limited effect on the prescription rates of these agents. We also found that the overall rates of use of these drugs actually increased between the first warning in 2002 and the end of our follow-up in 2007.

We did find some specific effects of the warnings. The first 2 warnings named a single atypical drug, and in each case the warning was associated with both relative and absolute decreases in the predicted growth in the use of these drugs. The relative decreases were substantial: by $11.8 \%$ for risperidone after the first warning and by $14.6 \%$ for olanzapine after the second warning. However, the warnings were also associated with effects on related drugs not named in the warnings. For example, although the first warning named only risperidone, it was associated with a decrease in the use of olanzapine and increases in the use of quetiapine and conventional antipsychotic agents. In the end, the warnings were at best associated with only small relative decreases in the predicted growth in the use of atypical antipsychotic drugs by $5.0 \%$ after the first warning, $4.9 \%$ after the second and $3.2 \%$ after the third. However, they were not associated with a decrease in the overall use of these drugs.

A recent Canadian study showed that a regulatory warning about prescribing antidepressants to children and adolescents had the desired effect of decreased rates of use in these age groups. ${ }^{12}$ However, the rates of use were also decreased among young adults, a population not identified in the warning. Other studies have suggested that warnings have little or no effect on drug utilization., ${ }^{3,13}$ In this context our findings suggest that warnings can have different effects in different situations and that their impact cannot be taken for granted.

Studies of the effects of warnings and the communication of risk suggest that warnings should be clear about the risks. ${ }^{14}$ Calculating the number needed to harm has been suggested as a better way to communicate drug risks to physicians than relative or absolute risks. ${ }^{15}$ This might be a useful strategy for Health Canada in future warnings. If the goal of the new in-

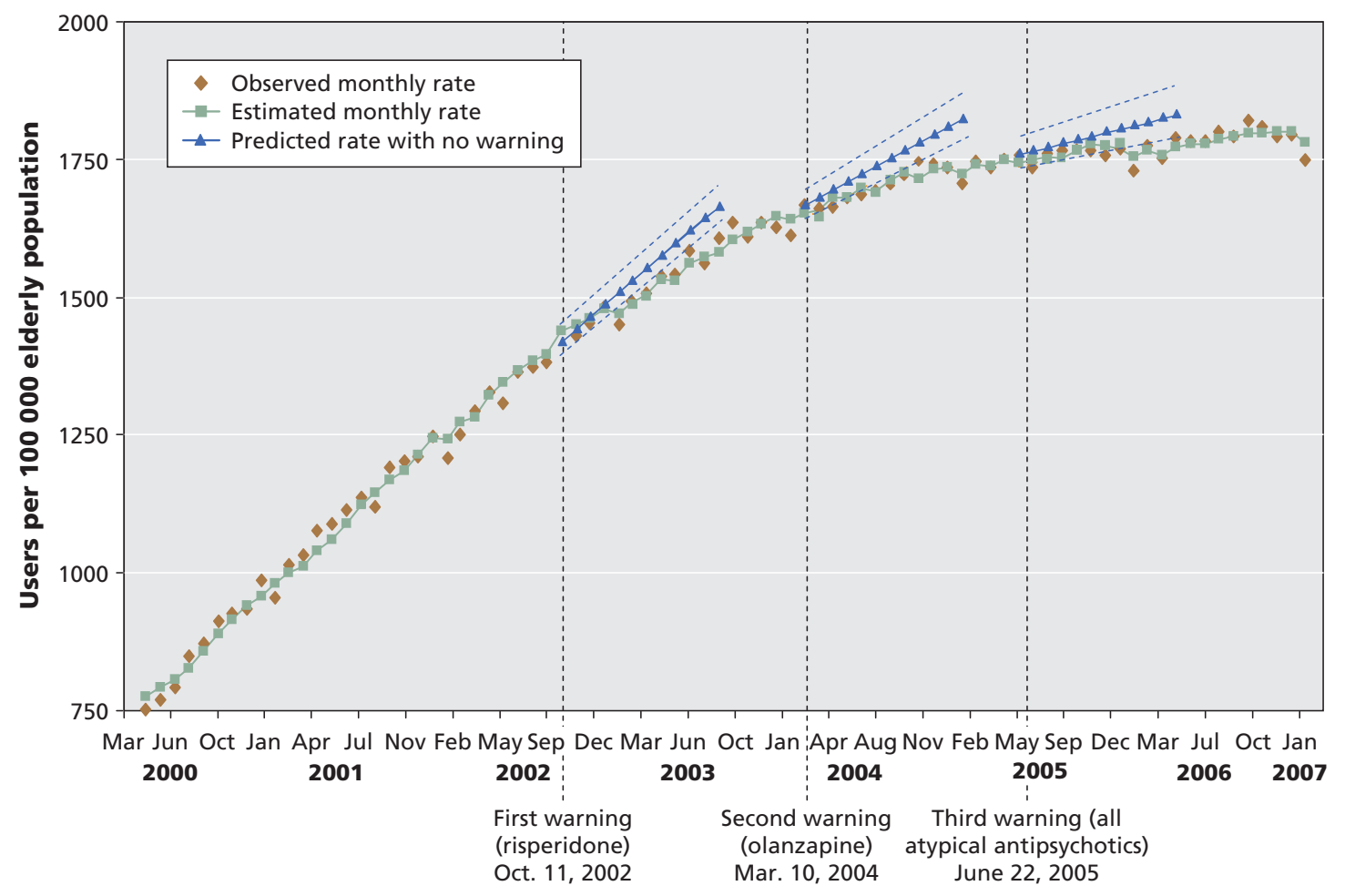

Figure 2: Estimated and predicted use of atypical antipsychotic drugs before and after 3 warnings of serious adverse events associated with atypical antipsychotic drugs in elderly patients with dementia. Estimated rates, and predicted rates without warnings, represent estimates from our interrupted time-series analysis. The dashed blue lines represent $95 \%$ confidence intervals around the predicted estimates. 


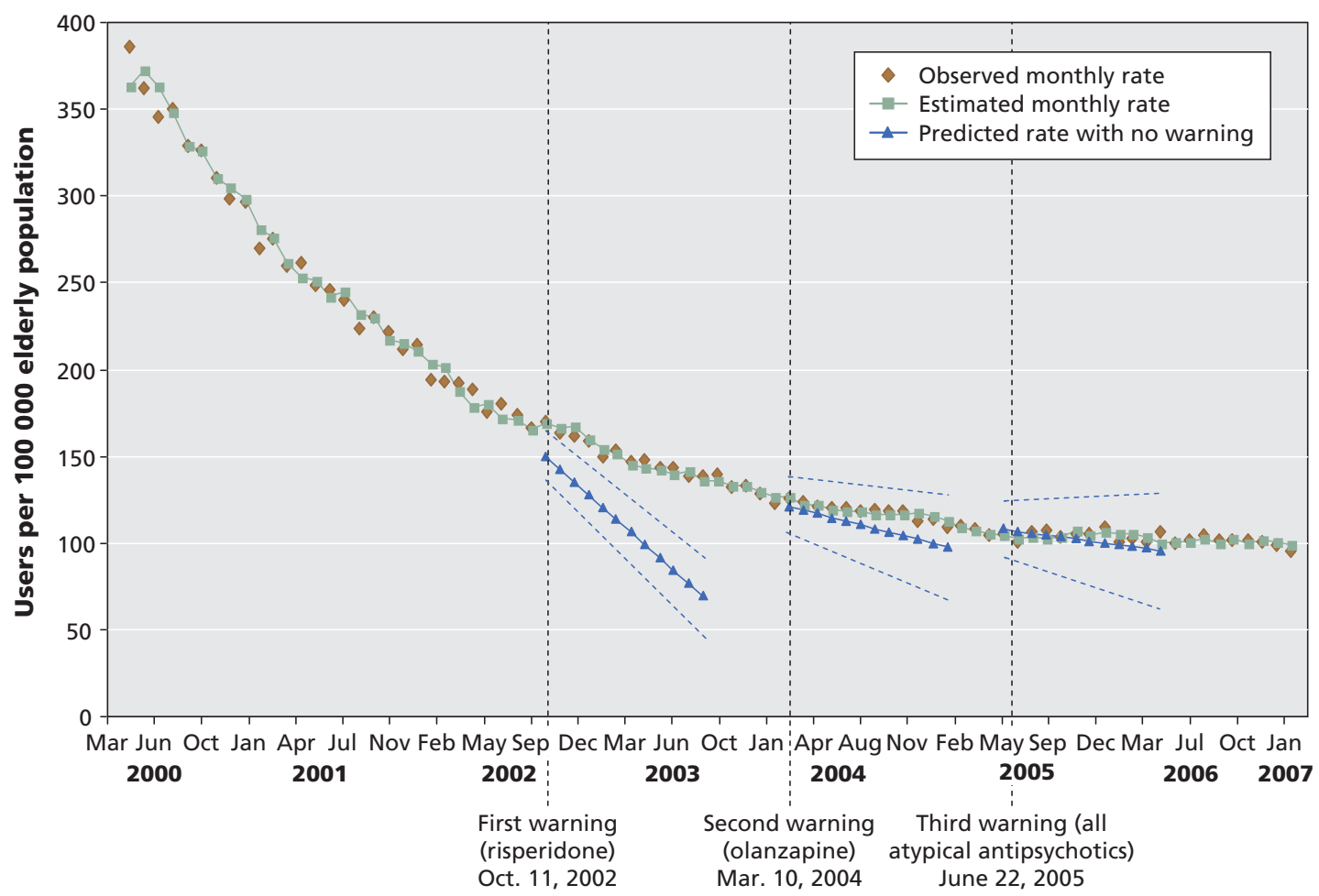

Figure 3: Estimated and predicted use of conventional antipsychotic drugs before and after 3 warnings of serious adverse events associated with atypical antipsychotic drugs in elderly patients with dementia. Estimated rates, and predicted rates without warnings, represent estimates from our interrupted time-series analysis. The dashed blue lines represent $95 \%$ confidence intervals around the predicted estimates.

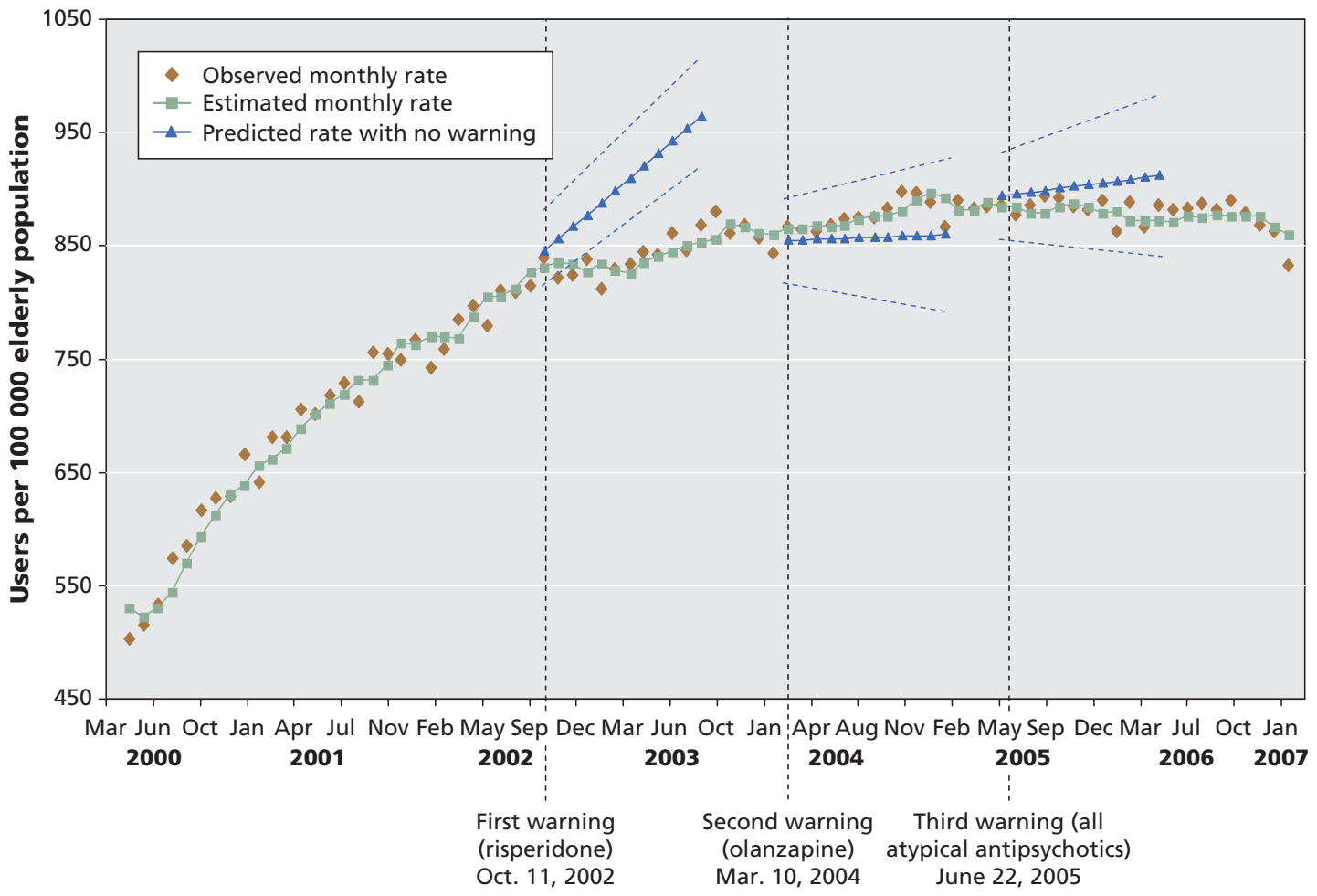

Figure 4: Estimated and predicted use of risperidone before and after 3 warnings of serious adverse events associated with atypical antipsychotic drugs in elderly patients with dementia. Estimated rates, and predicted rates without warnings, represent estimates from our interrupted time-series analysis. The dashed blue lines represent $95 \%$ confidence intervals around the predicted estimates. 


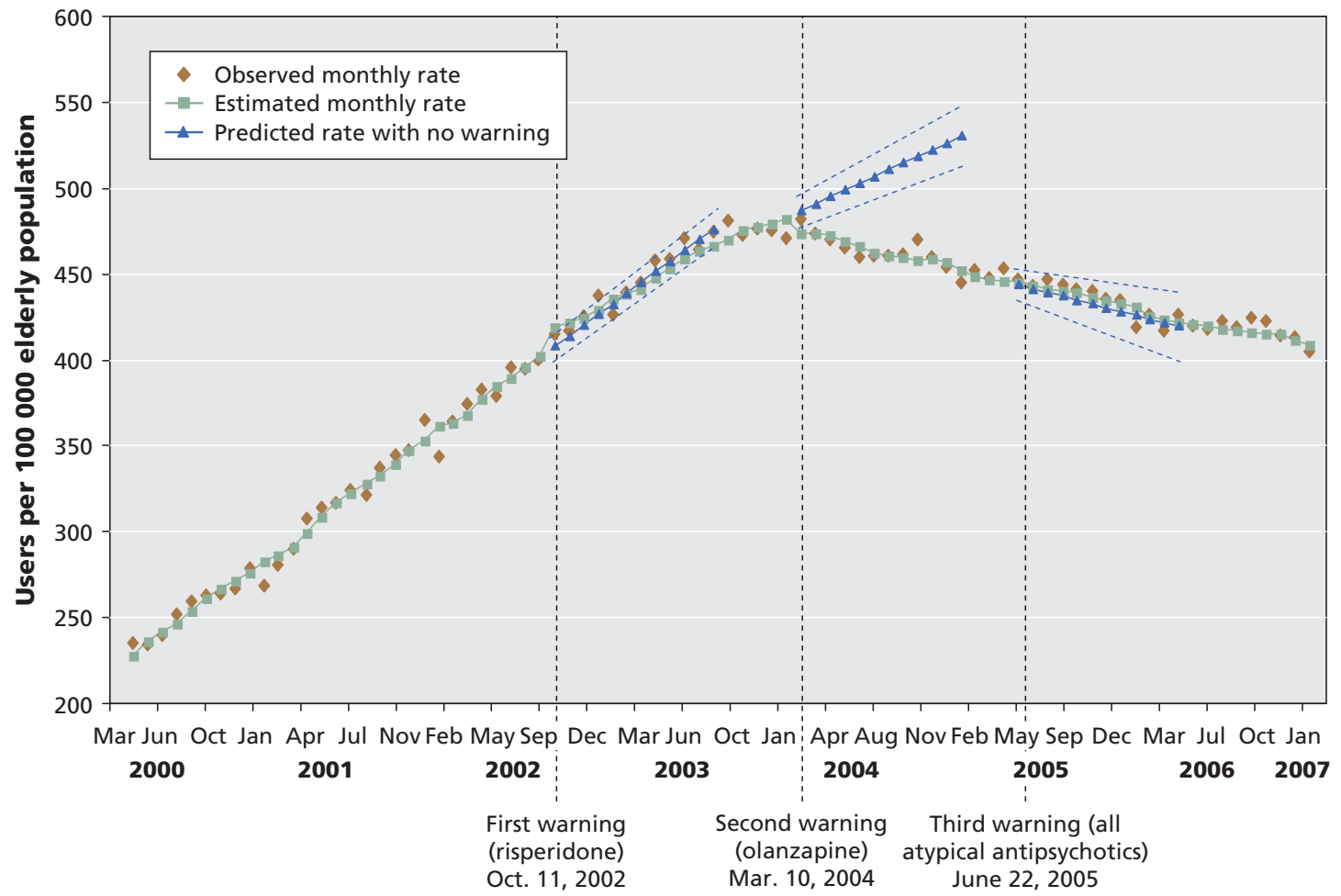

Figure 5: Estimated and predicted use of olanzapine before and after 3 warnings of serious adverse events associated with atypical antipsychotic drugs in elderly patients with dementia. Estimated rates, and predicted rates without warnings, represent estimates from our interrupted time-series analysis. The dashed blue lines represent $95 \%$ confidence intervals around the predicted estimates.

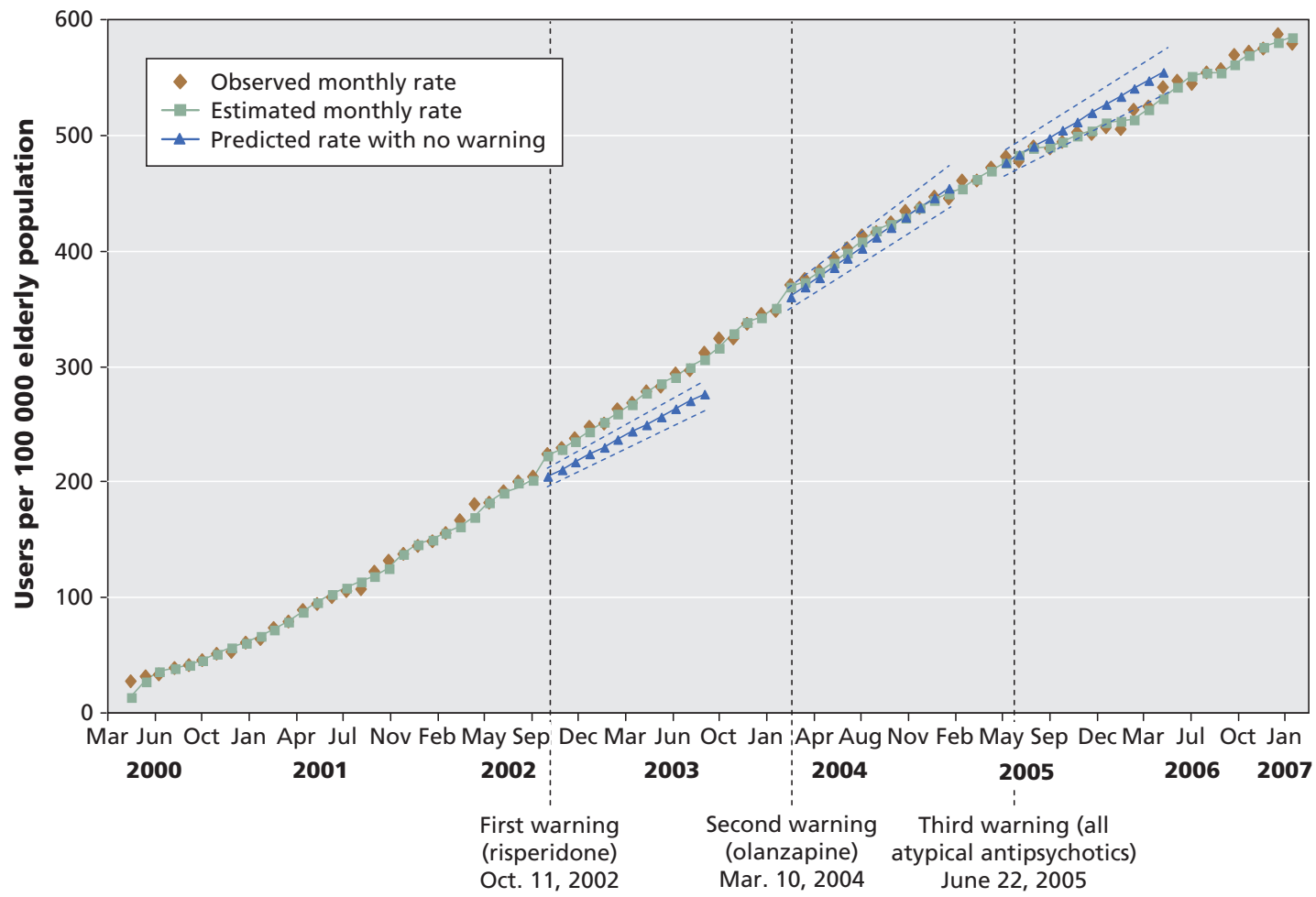

Figure 6: Estimated and predicted use of quetiapine before and after 3 warnings of serious adverse events associated with atypical antipsychotic drugs in elderly patients with dementia. Estimated rates, and predicted rates without warnings, represent estimates from our interrupted time-series analysis. The dashed blue lines represent $95 \%$ confidence intervals around the predicted estimates. 
formation on risk is to motivate prescribers to rethink their therapeutic options, perhaps the warnings should be clear about alternatives and their safety and efficacy. For example, for atypical antipsychotic drugs, this would include comment on the safety and efficacy of conventional antipsychotic agents. Interestingly, the warning from the US Food and Drug Administration clearly indicated that there were concerns about the safety of conventional antipsychotics, ${ }^{16}$ although this was not raised in the Health Canada warning. A more comprehensive view of alternatives should include at least a summary of nonpharmacologic interventions. For example, current clinical practice guidelines for the treatment of dementia include a range of nonpharmacologic interventions for dealing with aggression and agitation. ${ }^{17}$

It would also seem important for Health Canada to determine whether the warnings had their intended effects. Health Canada should conduct or commission well-designed evaluations of the impact of its warnings. Evaluation is particularly important in situations such as the use of antipsychotic agents in patients with dementia, among whom use of these drugs is common and the risks are high.

If Health Canada were to take a more proactive approach to assessing the impact of its warnings, it will also need a strategy for responding to situations where the warnings do not have the desired effect. To develop such a strategy, Health Canada should work with the others involved in drug prescribing in Canada - manufacturers, provincial and private insurers, and physicians.

Health Canada and other regulators are in a position to dictate the content of warnings so that they provide better information on risks and on alternatives. However, they may need to work in partnership with others to ensure that the message is adequately communicated. There are concerns that drug companies may not always provide complete information on drug safety. ${ }^{18}$ Although drug manufacturers are often involved in sending out letters warning of safety issues, perhaps more could be made of their expertise in marketing to ensure that safety messages are heard.

Most drugs in Canada are paid for by provincial drug plans or private insurers. The funders could play a more active role in responding to new safety information. ${ }^{19}$ They have the ability to change the terms and conditions under which drugs are funded, which can have a profound effect on rates of use..$^{20}$

Ultimately, physicians are responsible for prescribing drugs. They should be sensitive to new safety information and how it might influence their prescribing. Professional organizations can work toward developing and disseminating clini- cal guidelines that deal specifically with drug safety issues and that are responsive to changes in safety information.

A strength of our study is our use of utilization rates based on claims data from a comprehensive drug benefit program to provide a population-based analysis. Our study has limitations. The time-series analysis, although a powerful tool for assessing the effect of widely disseminated information on prescribing behaviour, is subject to threats to validity. ${ }^{21}$ The observed changes may have been the result of other factors coincident with the warnings. However, we were able to show changes in prescription rates specifically for the drugs named in the first 2 warnings, which suggests that the warnings had at least some effect. Warnings issued by regulatory agencies in other countries ${ }^{16,22-24}$ and articles on the risks of antipsychotic drugs ${ }^{25-29}$ may have contributed to the declines in use we observed in our study. Therefore, our finding of modest effects associated with the Health Canada warnings is, if anything, optimistic about the contribution of these warnings.

\section{Conclusion}

Despite 3 warnings about serious adverse events associated with atypical antipsychotic drugs in elderly patients with de- 
mentia, the overall rates of use of these drugs in this patient population increased. This finding highlights the limited impact of warnings and suggests that more effective approaches are needed to protect vulnerable populations from potentially hazardous medications. A comprehensive, coordinated approach involving Health Canada, drug manufacturers, private and public drug insurers, and physicians is needed.

This article has been peer reviewed.

Competing interests: Nathan Herrmann has been a consultant to and received travel assistance from Janssen-Ortho Inc. He has also received research support and speaker fees from Janssen-Ortho Inc., Eli Lilly, Pfizer and AstraZeneca, companies that market atypical antipsychotic drugs. No competing interests declared for Elmira Valiyeva, Paula Rochon, Sudeep Gill or Geoffrey Anderson.

Contributors: All of the authors were responsible for the study concept and design. Elmira Valiyeva was responsible for the acquisition of data. She, Sudeep Gill and Geoffrey Anderson analyzed and interpreted the data. All of the authors contributed to the writing of the manuscript and critically revised it for important intellectual content. Paula Rochon and Geoffrey Anderson were responsible for administrative, technical and material support, and Geoffrey Anderson supervised the study. Elmira Valiyeva had full access to all of the data in the study and takes responsibility for the integrity of the data and the accuracy of the data analysis. All of the authors approved the final version for publication.

Acknowledgements: Elmira Valiyeva was supported by a postdoctoral fellowship from the Department of Health Policy, Management and Evaluation, University of Toronto. Sudeep Gill was supported by a Career Scientist Award from the Ontario Ministry of Health and Long-Term Care. Geoffrey Anderson holds the Chair in Health Management Strategies at the University of Toronto.

Funding: This work was supported by a Canadian Institutes of Health Research (CIHR) Chronic Disease New Emerging Team program (NET-54010) and an Interdisciplinary Capacity Enhancement grant (H0A-80075). The New Emerging Team program receives joint sponsorship from the Canadian Diabetes Association, the Kidney Foundation of Canada, the Heart and Stroke Foundation of Canada, and the CIHR Institutes of Nutrition, Metabolism and Diabetes, and Circulatory and Respiratory Health.

\section{REFERENCES}

1. Hauptman PJ, Schnitzler MA, Swindle J, et al. Use of nesiritide before and after publications suggesting drug-related risks in patients with acute decompensated heart failure. JAMA 2006;296:1877-84

2. Kesselheim AS, Fischer MA, Avorn J. The rise and fall of Natrecor for congestive heart failure: implications for drug policy. Health Aff (Millwood) 2006;25:1095-102.

3. Shatin D, Gardner JS, Stergachis A, et al. Impact of mailed warning to prescribers on the co-prescription of tramadol and antidepressants. Pharmacoepidemiol Drug Saf 2005; 14:149-54.

4. Important drug safety information: Risperdal (risperidone) and cerebrovascular adverse events in placebo-controlled dementia trials [Dear Healthcare Professional letter from Janssen-Ortho]. Ottawa: Health Canada; 2002. Available: www.hc-sc .gc.ca/dhp-mps/medeff/advisories-avis/prof/_2002/risperdal_hpc-cps-eng.php (accessed 2008 May 5).

5. Zyprexa (olanzapine) and cerebrovascular adverse events in placebo-controlled elderly dementia trials [Dear Healthcare Professional letter from Eli Lilly]. Ottawa: Health Canada; 2004. Available: www.hc-sc.gc.ca/dhp-mps/medeff/advisoriesavis/prof/2004/zyprexa_hpc-cps-eng.php (accessed 2008 May 5).

6. Increased mortality associated with the use of atypical antipsychotic drugs in elderly patients with dementia [Dear Healthcare Professional letter]. Ottawa: Health
Canada; 2004. Available: www.hc-sc.gc.ca/dhp-mps/medeff/advisories-avis/prof /_2005/atyp-antipsycho_hpc-cps-eng.php (accessed 2008 May 5).

7. Wang PS, Schneeweiss S, Avorn J, et al. Risk of death in elderly users of conventional vs. atypical antipsychotic medications. N Engl J Med 2005;353:2335-41.

8. Gill SS, Bronskill SE, Normand SLT, et al. Antipsychotic drug use and mortality in older adults with dementia. Ann Intern Med 2007;146:775-86.

9. Levy AR, O'Brien BJ, Sellors G, et al. Coding accuracy of administrative drug claims in the Ontario Drug Benefit database. Can J Clin Pharmacol 2003;10:67-71.

10. Gill SS, Rochon PA, Herrmann N, et al. Atypical antipsychotic drugs and risk of ischaemic stroke: population based retrospective cohort study. BMJ 2005:330:445.

11. Wagner AK, Soumerai SB, Zhang F, et al. Segmented regression analysis of interrupted time series studies in medication use research. J Clin Pharm Ther 2002;27: 299-309.

12. Katz LY, Kozyrskyj AL, Prior HJ, et al. Effect of regulatory warnings on antidepressant prescription rates, use of health services and outcomes among children, adolescents and young adults. CMAJ 2008;178:1005-11.

13. Smalley W, Shatin D, Wysowski DK, et al. Contraindicated use of cisapride: impact of Food and Drug Administration regulatory action. JAMA 2000;284:3036-9.

14. Goldman SA. Communication of medical product risk: How effective is effective enough? Drug Saf 2004;27:519-34.

15. Edwards A, Elwyn G. Understanding risk and lessons for clinical risk communication about treatment preferences. Qual Health Care 2001;10(suppl I):i9-13.

16. US Food and Drug Administration. Deaths with antipsychotics in elderly patients with behavioral disturbances [public health advisory]. Washington (DC): Department of Health and Human Services; 2005. Available at: www.fda.gov/Cder/drug /advisory/antipsychotics.htm (accessed 2008 May 14).

17. Herrmann N, Gauthier S, Lysy P. Clinical practice guidelines for severe Alzheimer's disease. Alzheimer Demen 2007;3:385-97.

18. US Food and Drug Administration. Seroquel (quetiapine) tablets [letter]. Washinton (DC): Department of Health and Human Services; 2006. Available: www.fda .gov/cder/warn/2006/Seroquel_letter.pdf (accessed 2008 May 5).

19. Polinski JM, Wang PS, Fischer MA. Medicaid's prior authorization program and access to atypical antipsychotic medications. Health Af (Millwood) 2007;26:750-60.

20. Marshall DA, Willison DJ, Grootendorst P, et al. The effects of coxib formulary restrictions on analgesic use and cost: regional evidence from Canada. Health Policy 2007;84:1-13.

21. Ramsay CR, Matowe L, Grilli R, et al. Interrupted time series designs in health technology assessment: lessons from two reviews of behaviour change strategies. Int J Technol Assess Health Care 2003;19:613-23.

22. US Food and Drug Administration. 2003 safety alert - Risperdal (risperidone) [letter from Janssen Pharmaceutica Inc.]. Washington (DC): Department of Health and Human Services; 2003. Available: www.fda.gov/medwatch/SAFETY/2003 /risperdal.htm (accessed 2008 May 5).

23. US Food and Drug Administration. Warning about Zyprexa (olanzapine) [FDA Patient Safety News podcast, show no. 27]. Washington (DC): Department of Health and Human Services; May 2004. Available: www.accessdata.fda.gov /scripts/cdrh/cfdocs/psn/transcript.cfm?show=27\#6 (accessed 2008 May 5).

24. Duff G. Atypical antipsychotic drugs and stroke. London (UK): Department of Health; 2004. Available: www.info.doh.gov.uk/doh/embroadcast.nsf/vwDiscussionAll/ 3D8DBB48B26FF90280256E520045977A (accessed 2008 May 5).

25. Schneider LS, Dagerman KS, Insel P. Risk of death with atypical antipsychotic drug treatment for dementia, meta-analysis of randomized placebo-controlled trials. JAMA 2005;294:1934-43.

26. Wooltorton E. Risperidone (Risperdal): increased rate of cerebrovascular events in dementia trials. CMAJ 2002;167:1269-70.

27. Wooltorton E. Olanzapine (Zyprexa): increased incidence of cerebrovascular events in dementia trials. CMAJ 2004:170:1395.

28. Rabins PV, Lyketsos CG. Antipsychotic drugs in dementia. What should be made of the risks? JAMA 2005;294:1963-5.

29. Kuehn BM. FDA warns antipsychotic drugs may be risky for elderly. JAMA 2005;293:2462.

Correspondence to: Dr. Elmira Valiyeva, Department of Health Policy, Management and Evaluation, Faculty of Medicine,

University of Toronto, 425-155 College St., Toronto ON M5T 3M6; fax 416 978-7350; elmira.valiyeva@utoronto.ca 